\title{
Electrospun polyporous VN nanofibers for symmetric all-solid-state supercapacitors
}

\author{
Dandan ZHANG, Jing LI, Zhen SU, Sanyuan HU, Heping LI*, Youwei YAN \\ State Key Laboratory of Materials Processing and Die \& Mould Technology, School of Materials Science \\ and Engineering, Huazhong University of Science and Technology, Wuhan 430074, China
}

Received: December 22, 2017; Revised: March 24, 2018; Accepted: April 02, 2018

(C) The Author(s) 2018. This article is published with open access at Springerlink.com

\begin{abstract}
To promote the energy density of symmetric all-solid-state supercapacitors (SCs), efforts have been dedicated to searching for high-performance electrode materials recently. In this paper, vanadium nitride (VN) nanofibers with mesoporous structure have been fabricated by a facile electrospinning method. Their crystal structures and morphology features were characterized by X-ray diffraction, scanning electron microscopy, and transmission electron microscopy. The mesoporous structure of VN nanofibers, which can provide short electrolyte diffusion routes and conducting electron transport pathways, is beneficial to their performance as a supercapacitor electrode. Under a stable electrochemical window of $1.0 \mathrm{~V}, \mathrm{VN}$ nanofibers possess an excellent mass specific capacitance of $110.8 \mathrm{~F} / \mathrm{g}$ at a scan rate of $5 \mathrm{mV} / \mathrm{s}$. Moreover, the $\mathrm{VN}$ nanofibers were further assembled into symmetric all-solid-state SCs, achieving a high energy density of $0.89 \mathrm{~mW} \cdot \mathrm{h} / \mathrm{cm}^{3}$ and a high power density of $0.016 \mathrm{~W} / \mathrm{cm}^{3}$ over an operating potential range from 0 to $1.0 \mathrm{~V}$. These results demonstrate that $\mathrm{VN}$ nanofibers could be potentially used for energy storage devices.
\end{abstract}

Keywords: vanadium nitride (VN); mesoporous structure; nanofiber; supercapacitors (SCs); electrospinning

\section{Introduction}

The great achievements in electronics aggregating the high performance and the tiny dimension have been attained [1,2]. Supercapacitors (SCs) meet the above requirements. Motivated by the increasing demand of portable/wearable electronics [3], SCs have attracted immense interest because of their outstanding performances, such as superior power density, fast charge/discharge rate, and long cycle lifetime [4-8]. These outstanding properties enable SCs to be applied in various energy fields like solar photo-electricity

* Corresponding author.

E-mail: liheping@hust.edu.cn products, electric vehicles, and so forth $[9,10]$.

Generally, SCs are classified into electric double layer capacitors (EDLCs) and pseudo capacitors in terms of their charge-storage mechanism [11]. The EDLCs can store charge at the electrode-electrolyte interface, and the capacitance arises from charge accumulation $[12,13]$, whereas the pseudo capacitors are based on the fast and reversible redox reactions that occur on the electrode surface [14]. During the past decades, particular attention has been paid to developing high performance electrode materials for SCs [15-18]. Promising materials including active carbon, carbon nanotubes (CNTs), and graphene have been investigated [19]. However, these materials still face several difficult issues, such as low average 
specific capacitance and low energy density [20], which need to be addressed for their application. In this context, the development of alternative materials with an ultra-high performance for SCs is of vital importance undoubtedly.

Nowadays, transition metal compounds have attracted increasing attention due to their relatively high capacitance [21,22]. As reported previously, much effort has been dedicated to studying the electrochemical features of transition metal oxides. Kumar et al. [23] fabricated $\mathrm{Co}_{3} \mathrm{O}_{4}$ nanofibers as electrode material for asymmetric SCs, achieving a specific capacitance of $407 \mathrm{~F} / \mathrm{g}$ at a scan rate of $5 \mathrm{mV} / \mathrm{s}$. Devadas et al. [24] applied $\mathrm{RuO}_{2}$ nanoparticles to capacitors as electrode, which showed the specific capacitance of $716 \mathrm{~F} / \mathrm{g}$ at 5 $\mathrm{mV} / \mathrm{s}$. At the same time, transition metal nitrides have aroused numerous interests for application in energy storage devices, such as vanadium nitride (VN), titanium nitride $(\mathrm{TiN})$, molybdenum nitride $\left(\mathrm{Mo}_{x} \mathrm{~N}\right)$, tungsten nitride $(\mathrm{WN})$, and nickel nitride $\left(\mathrm{NiN}_{x}\right)$, due to their excellent electrochemical stability and high electrical conductivity [25-31]. Zhou et al. [32] mixed nano-VN powders with graphite powders and acetylene black for SCs, which exhibited a specific capacitance of $161 \mathrm{~F} / \mathrm{g}$ at $30 \mathrm{mV} / \mathrm{s}$. Lu et al. [33] fabricated VN nanowires through a hydrothermal method and achieved an excellent specific capacitance of $298.5 \mathrm{~F} / \mathrm{g}$ at a scan rate of $10 \mathrm{mV} / \mathrm{s}$. These advances indicate that $\mathrm{VN}$ could be a promising material in energy storage filed, such as SC, battery, etc. [31]. In addition, VN with a stable working window both in solid and solution electrolyte is suitable for using in SCs [34]. However, most studies on VN-based SCs have added the conductive additive in the electrode [29-33]. The intrinsic performance of $\mathrm{VN}$ nanofibers has been scarce reported. Herein, we have synthesized porous VN nanofibers by a facile electrospinning method and evaluated their properties by assembling the obtained VN nanofibers into symmetric all-solid-state SCs [35-38].

\section{Experimental}

\section{1 Fabrication of VN nanofibers}

Figure 1 schematically shows the fabrication process of VN nanofibers. All reagents were of analytical grade and were used without further purification. Vanadium (V) oxytriisopropoxide $\left(\mathrm{C}_{9} \mathrm{H}_{21} \mathrm{O}_{4} \mathrm{~V}, M_{\mathrm{w}}=244.20\right.$, Aladdin Industrial Co., China) was chosen as the starting material. $\mathrm{C}_{9} \mathrm{H}_{21} \mathrm{O}_{4} \mathrm{~V}(9.8 \mathrm{wt} \%)$ and polyvinylpyrrolidone (PVP, $M_{\mathrm{w}}=1300000$, Aladdin Industrial Co., China) (5.0 $\mathrm{wt} \%$ ) were dissolved in a mixture of isopropanol and acetic acid $(2.5: 1=w: w)$. After continuous stirring for $6 \mathrm{~h}$ at room temperature, the solution became clear and was used for electrospinning. The precursor nanofibers were electrospun via a typical electrospinning setup as previously reported [39,40]. The peeled-off membranes were firstly calcined in air at $500{ }^{\circ} \mathrm{C}$ for $2 \mathrm{~h}$ to obtain $\mathrm{V}_{2} \mathrm{O}_{5}$ nanofibers. Afterwards,

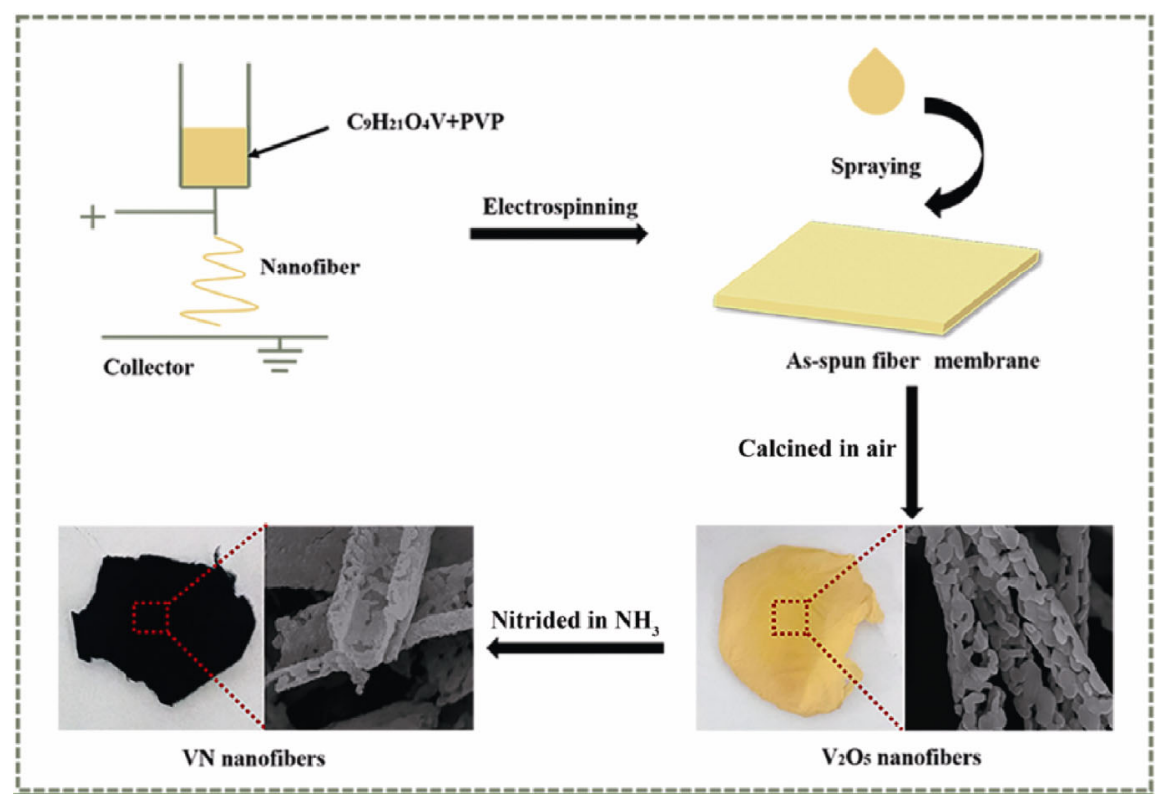

Fig. 1 Schematic illustration for fabricating VN nanofibers. 
the $\mathrm{V}_{2} \mathrm{O}_{5}$ nanofibers were converted into $\mathrm{VN}$ nanofibers by calcination under flowing ammonia atmosphere at a temperature ranging from 550 to $650{ }^{\circ} \mathrm{C}$.

\section{2 Material characterization}

The morphology and crystal structure of both $\mathrm{V}_{2} \mathrm{O}_{5}$ and $\mathrm{VN}$ nanofibers were characterized by field emission scanning electron microscopy (FESEM, NovaNano SEM 450, FEI, Netherlands) and X-ray diffraction (XRD, X'pert PRO, PANalytical B.V., Netherlands). Field transmission electron microscopy (FTEM, Tecnai G2 F30, FEI, Netherlands) was used to observe the microstructure of the fibers. The specific surface area and the pore size distribution were obtained by a Brunauer-Emmett-Teller (BET) nitrogen adsorption/ desorption measurement (Micromeritics ASAP 2020, America).

\section{3 Assembling of VN nanofiber-based all-solid- state SCs}

Due to the high electrical conductivity of VN (1.17x $10^{6} \mathrm{~S} / \mathrm{m}$ ) [30], the conductive additive is not added for the sake of assessing the intrinsic capacitance characteristic of the porous $\mathrm{VN}$ nanofibers. $90 \mathrm{wt} \%$ of $\mathrm{VN}, 10 \mathrm{wt} \%$ of polyvinylidene fluoride (PVDF) and methyl-2-pyrrolidone (NMP) solvent were mixed homogeneously and then transferred onto an ITO glass that was employed as a current collector. The electrodes were heated at $60{ }^{\circ} \mathrm{C}$ for $6 \mathrm{~h}$ in an oven. Afterwards, $\mathrm{LiCl} / \mathrm{PVA}$ solid-state electrolyte was brushed equably onto the VN-coated ITO glass, followed by drying at $60{ }^{\circ} \mathrm{C}$ for $6 \mathrm{~h}$. After removing all the extra moisture, two electrodes were assembled together into SCs.

\section{4 Electrochemical measurements}

The SCs performance was evaluated by cyclic voltammetry (CV), galvanostatic discharge/charge (GDC) measurements, and electrochemical impedance spectroscopy (EIS) on the electrochemical workstation (CHI-760E, Chenhua, Shanghai, China) at room temperature. All electrochemical measurements were carried out using a two-electrode cell configuration with $\mathrm{LiCl} / \mathrm{PVA}$ gel as the electrolyte and PVDF as the binder.

\section{Results and discussion}

Figure 1 schematically shows the fabrication procedure of VN nanofibers. The electrospun precursor nanofibers were transformed into $\mathrm{VN}$ nanofibers by a two-stage heat treatment process. At the first stage, the precursor nanofibers were calcined in air at $500{ }^{\circ} \mathrm{C}$ to obtain $\mathrm{V}_{2} \mathrm{O}_{5}$ nanofibers. Afterwards, the resultant $\mathrm{V}_{2} \mathrm{O}_{5}$ nanofibers were calcined in ammonia atmosphere to produce $\mathrm{VN}$ counterparts based on the following reaction:

$$
3 \mathrm{~V}_{2} \mathrm{O}_{5}+10 \mathrm{NH}_{3} \rightarrow 6 \mathrm{VN}+2 \mathrm{~N}_{2} \uparrow+15 \mathrm{H}_{2} \mathrm{O} \uparrow
$$

The morphology of both $\mathrm{V}_{2} \mathrm{O}_{5}$ and $\mathrm{VN}$ nanofibers were characterized by scanning electron microscopy (SEM), as shown in Fig. 2. Interestingly, $\mathrm{V}_{2} \mathrm{O}_{5}$ nanofibers have a polyporous structure (Fig. 2(a)), which may be ascribed to the decomposition of high-molecular polymer (PVP) contained in the precursor nanofibers [36]. These $\mathrm{V}_{2} \mathrm{O}_{5}$ nanofibers remained intact after calcining and were continuous with length up to several micrometers. The polyporous $\mathrm{V}_{2} \mathrm{O}_{5}$ nanofibers were nitrided at 550,600 , and $650{ }^{\circ} \mathrm{C}$ to fabricate VN nanofibers. As seen in Figs. 2(b)-2(d), the resultant VN nanofibers were broken into short parts with diameter ranging from 250 to $450 \mathrm{~nm}$. With the calcining temperature increasing, pores in the $\mathrm{VN}$ fibers were reduced gradually, leading to a compact surface. The elimination of pores was speculated to be caused by the growth of $\mathrm{VN}$ grain during calcination in ammonia.

To investigate the microstructure of the $\mathrm{VN}$ nanofibers, TEM characterization was further conducted. In the high resolution TEM image (Fig. 3(a)), the spacing $d$ of the crystal lattice is calculated to be 2.05 and $2.35 \AA$, respectively, which corresponds to the (200) and (111) planes of cubic VN. The selected area electron diffraction (SAED) (Fig. 3(b)) demonstrates the polycrystalline structure of the $\mathrm{VN}$ nanofibers [41].

The phase constitution of $\mathrm{V}_{2} \mathrm{O}_{5}$ and $\mathrm{VN}$ nanofibers are also confirmed by X-ray diffraction (XRD). In Fig. 4, the strong diffraction peaks from pre-oxidized products (Fig. 4(a)) could be assigned to (200), (001), (101), (110), and (301) lattice planes of $\mathrm{V}_{2} \mathrm{O}_{5}$ [40]. After calcining in ammonia above $500{ }^{\circ} \mathrm{C}$, all the $\mathrm{V}_{2} \mathrm{O}_{5}$ peaks disappear and the emerging peaks agree well with the (111), (200), (220), (311), and (222) diffraction peaks of cubic $\mathrm{VN}$, indicating the successful fabrication of $\mathrm{VN}$ nanofibers via electrospinning [41,42]. The crystallite size of VN nanofibers is calculated by employing the Debye-Scherrer equation:

$$
d=k \lambda / \beta \cos \theta
$$

where $d$ is the linear dimension of the crystal size (nm), $k$ is the spherical shape factor (0.89), $\lambda$ is the X-ray 


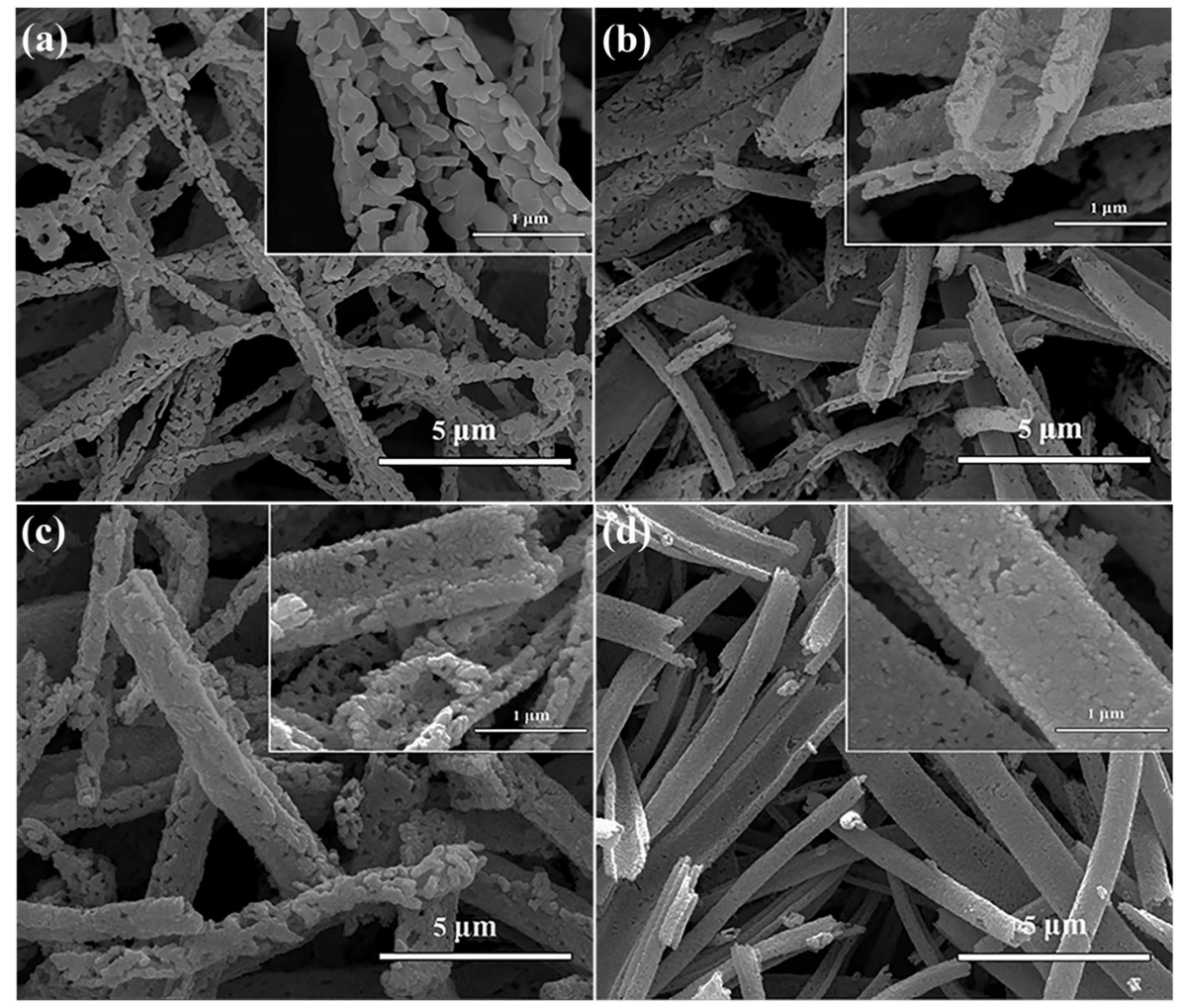

Fig. 2 (a) SEM images of $\mathrm{V}_{2} \mathrm{O}_{5}$ nanofibers, and SEM images of VN nanofibers nitrided at (b) 550, (c) 600 , and (d) $650{ }^{\circ} \mathrm{C}$. Insets: the corresponding high resolution SEM images.
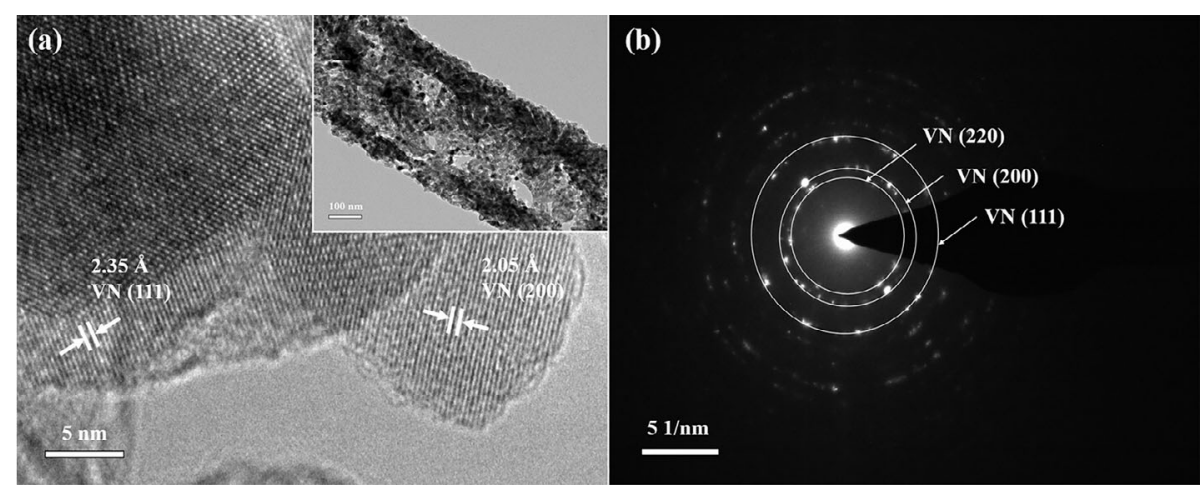

Fig. 3 (a) TEM images and (b) SAED pattern of an individual VN nanofiber nitrided at $550{ }^{\circ} \mathrm{C}$ in ammonia.
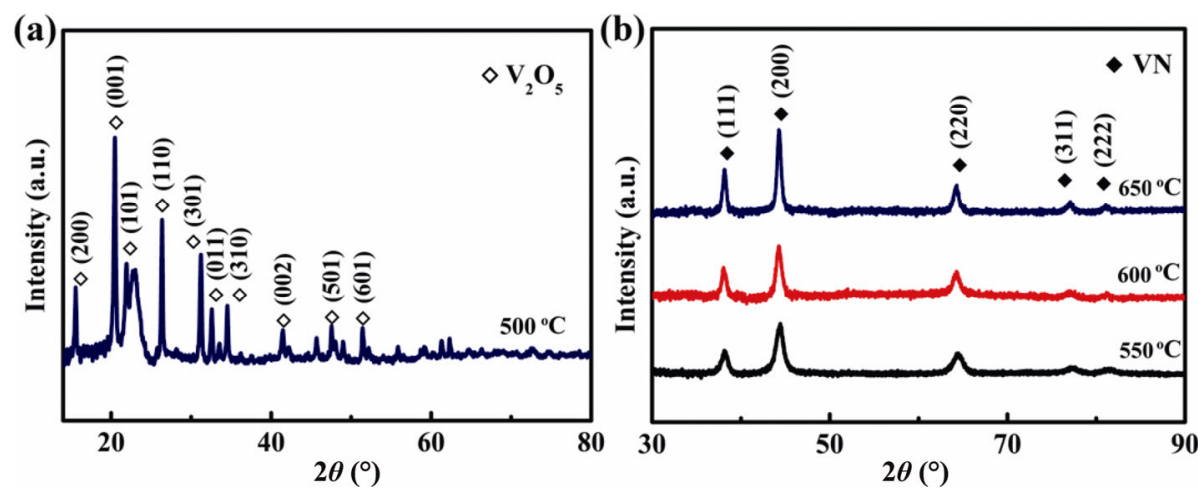

Fig. 4 XRD patterns of (a) $\mathrm{V}_{2} \mathrm{O}_{5}$ nanofibers and (b) $\mathrm{VN}$ nanofibers nitrided at 550, 600, and $650{ }^{\circ} \mathrm{C}$ in ammonia. 
wavelength $(0.154056 \mathrm{~nm}), \beta$ is the full width at half-maximum height of the respective peak (rad), and $\theta$ is the diffraction angle $\left({ }^{\circ}\right)$. VN nanofibers nitrided at 550,600 , and $650{ }^{\circ} \mathrm{C}$ have an average size of 8.13 , 10.94, and $15.22 \mathrm{~nm}$, respectively. The crystallite size increases with the calcining temperature going up. The XRD data is in accord with the SEM and TEM results.

The $\mathrm{N}_{2}$ adsorption-desorption isotherms of the VN nanofibers show a type II hysteresis loop (Fig. S1 in the Electronic Supplementary Material (ESM)), which demonstrates the presence of three-dimensional-network pores with different sizes. As calculated by the BET method, the specific surface area of VN nanofibers nitrided at $550{ }^{\circ} \mathrm{C}$ is $37.62 \mathrm{~m}^{2} / \mathrm{g}$ with a relatively total pore volume of $0.18 \mathrm{~cm}^{3} / \mathrm{g}$, slightly larger than those nitrided at $600{ }^{\circ} \mathrm{C} \quad\left(30.97 \mathrm{~m}^{2} / \mathrm{g}, 0.17 \mathrm{~cm}^{3} / \mathrm{g}\right)$ and $650{ }^{\circ} \mathrm{C}\left(27.78 \mathrm{~m}^{2} / \mathrm{g}, 0.16 \mathrm{~cm}^{3} / \mathrm{g}\right.$ ) (Table $\mathrm{S} 1$ in the ESM) [43]. Ideally, the higher specific surface area of nanofibers could supply more active sites and efficiently promote electrolyte and ion diffusion, resulting in a better electrochemical performance despite other influencing factors [44-46]. Therefore, the VN nanofibers nitrided at $550{ }^{\circ} \mathrm{C}$ possess a great potential for exhibiting a more favorable double-layer capacitance.

The obtained VN nanofibers were further assembled into symmetric all-solid-state SCs as illustrated in Fig. 5. Afterwards, a two-electrode cell is adopted to assess the performance of $\mathrm{VN}$ nanofibers for its application in SCs, using $\mathrm{LiCl} / \mathrm{PVA}$ as solid-state electrolyte. Figure 6(a) shows the cyclic voltammetry (CV) performance of the VN nanofibers nitrided at $550{ }^{\circ} \mathrm{C}$ within a scan rate varying from 5 to $200 \mathrm{mV} / \mathrm{s}$ under a stable electrochemical window of $0-1.0 \mathrm{~V}$. The $\mathrm{CV}$ profiles of other samples are displayed in Fig. S2 in the ESM. All the CV curves exhibit a rectangularlike shape with low variance at high scan rates, revealing a typical double-layer capacitance behavior. The mass specific capacitances are calculated based on the following equation:

$$
C_{\mathrm{m}}=\frac{Q}{2 \times \Delta V \times 0.9 m \times v} \times 4
$$

where $C_{\mathrm{m}}$ is the mass specific capacitance $(\mathrm{F} / \mathrm{g}), Q$ is the quantity of electricity (C) by integrating the $\mathrm{CV}$ curves, $m$ is the gross mass ( $\mathrm{g}$ ) of the materials coated on the two working electrodes containing $\mathrm{VN}(90 \mathrm{wt} \%)$ and PVDF binder $(10 \mathrm{wt} \%), \Delta V$ is the potential window $(\mathrm{V})$, and $v$ is the scan rate $(\mathrm{mV} / \mathrm{s})$. As calculated by above equation, the nanofibers nitrided at $550{ }^{\circ} \mathrm{C}$ can achieve a highest capacitance value of $110.8 \mathrm{~F} / \mathrm{g}$ at $5 \mathrm{mV} / \mathrm{s}$. This achieved considerable mass specific capacitance might be attributed to two reasons as follows. Firstly, one-dimensional VN nanofibers can provide a large active surface area, which conduces to a shorten electron transport pathway. On the other hand, the mesoporous structure of $\mathrm{VN}$ nanofibers leads to fast electrolyte diffusion and lowers the charge transfer resistance. All of the above mentioned factors could enhance the performance of the SCs.

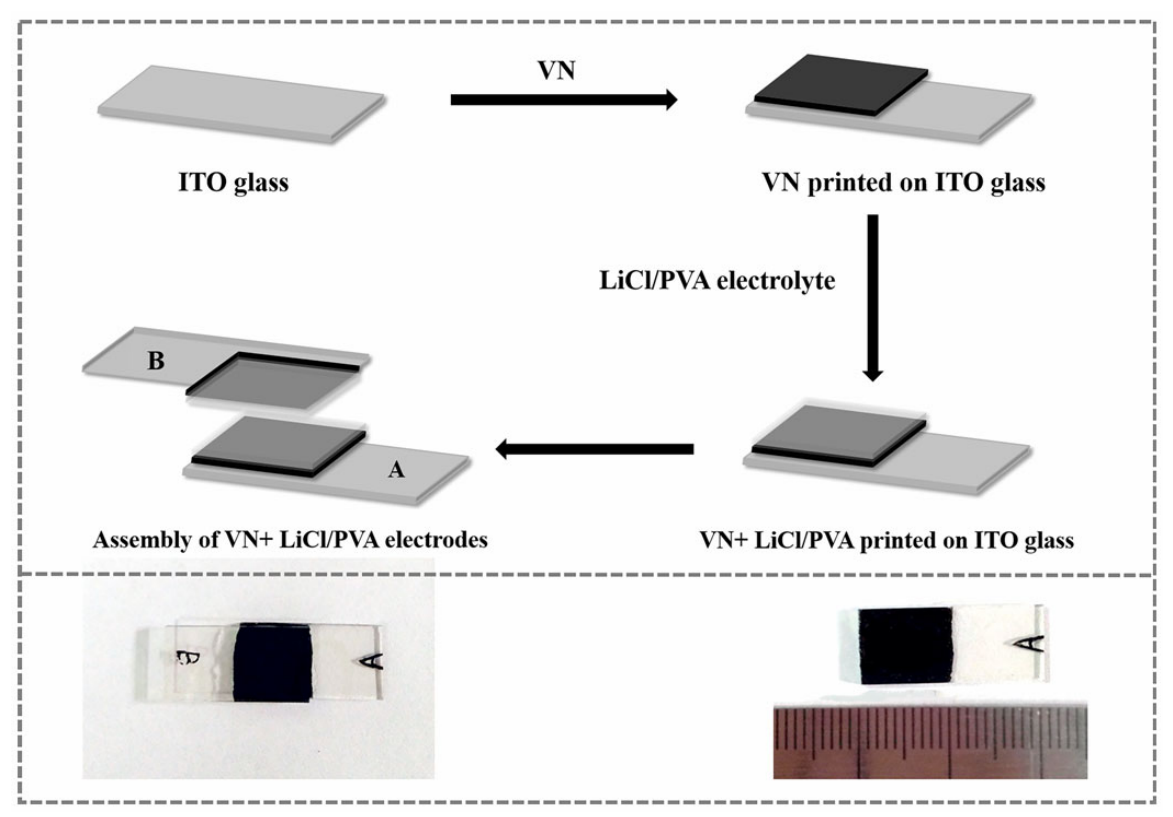

Fig. 5 Overall assembly procedure of VN nanofiber-based all-solid-state SCs. 

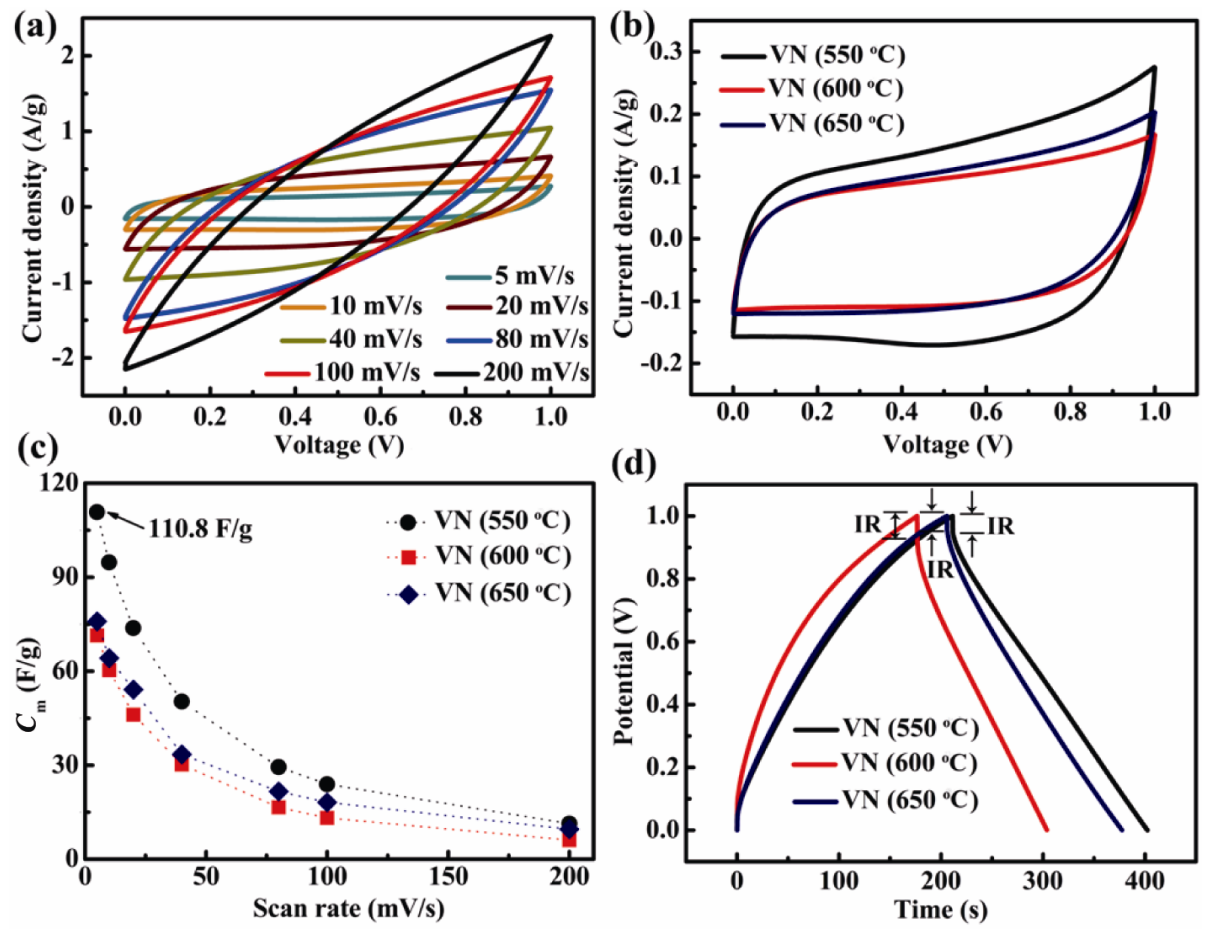

Fig. 6 (a) CV curves of VN nanofibers nitrided at $550{ }^{\circ} \mathrm{C}$ tested at various scan rate from 5 to $200 \mathrm{mV} / \mathrm{s}$; (b) $\mathrm{CV}$ curves of all the samples at a scan rate of $5 \mathrm{mV} / \mathrm{s}$; (c) $C_{\mathrm{m}}$ of these three samples plotted as a function of scan rate; (d) GDC curves collected from all the samples at $0.1 \mathrm{~A} / \mathrm{g}$.

CV curves of all the samples are shown in Fig. 6(b), which indicate that the capacitance of the $\mathrm{VN}$ nanofibers nitrided at $550{ }^{\circ} \mathrm{C}$ is higher than that of the ones nitrided at 600 and $650{ }^{\circ} \mathrm{C}$. It could be attributed to more porous-fibrous structure with smaller $\mathrm{VN}$ nano-grains which increase cross-linked paths and holes for the adsorption of electrolyte. Herein, the nano-porous morphology and suitable crystal size promote the higher mass specific capacitance of VN nanofibers nitrided at $550{ }^{\circ} \mathrm{C}$. And a slight deviation in $\mathrm{CV}$ curves is observed in the voltammetric response because of the rate-limiting phenomena supposedly [47]. The corresponding mass specific capacitance of these three samples is plotted as a function of scan rate (Fig. 6(c)). VN nanofibers nitrided at $550{ }^{\circ} \mathrm{C}$ exhibit a highest mass specific capacitance of $110.8 \mathrm{~F} / \mathrm{g}$ at $5 \mathrm{mV} / \mathrm{s}$, as compared to the ones nitrided at 600 and $650{ }^{\circ} \mathrm{C}$ with 71.5 and $76.0 \mathrm{~F} / \mathrm{g}$, respectively.

The galvanostatic discharge/charge (GDC) curves of all the samples at a current density of $0.1 \mathrm{~A} / \mathrm{g}$ are displayed in Fig. 6(d). The GDC curves at other current densities are shown in Fig. S3 in the ESM. The symmetric triangular shape implies an excellent electric double-layer capacitance property [48], which is ascribed to a combination of high specific surface area, small particle size, and nano-porous structure of VN nanofibers according to the aforementioned analysis. The VN nanofibers nitrided at $550{ }^{\circ} \mathrm{C}$ not only exhibit the maximum discharge time but also show slightly lower "IR drop" than the other samples. This result indicates the lower internal resistance of the VN nanofibers nitrided at $550{ }^{\circ} \mathrm{C}$. The specific capacitances $\left(C_{\mathrm{s}}\right)$ are calculated from their GDC curves on the basis of following formula:

$$
C_{\mathrm{s}}=\frac{I \times \Delta t}{\Delta V \times 0.9 m} \times 4
$$

where $I, \Delta t, \Delta V$, and $m$ are the constant current (A), discharging time (s), potential window during the discharge process after "IR drop" $(\mathrm{V})$, and the total mass of the materials coated on two working electrodes $(\mathrm{g})$ including $\mathrm{VN}(90 \mathrm{wt} \%)$ and binder PVDF (10 wt $\%$ ), respectively. The $C_{\mathrm{s}}$ of a single electrode is $82.84 \mathrm{~F} / \mathrm{g}$ at a current density of $0.1 \mathrm{~A} / \mathrm{g}$ when VN nanofibers were nitrided at $550{ }^{\circ} \mathrm{C}$, demonstrating a good rate performance [49]. We infer that capacitive characteristic could be attributed to the contribution of the good adsorption of electrolyte and ion transport as well as favorable conductivity of $\mathrm{VN}$ nanofibers. These results fully suggest a good doublelayer performance of the $\mathrm{VN}$ nanofiber-based symmetric 


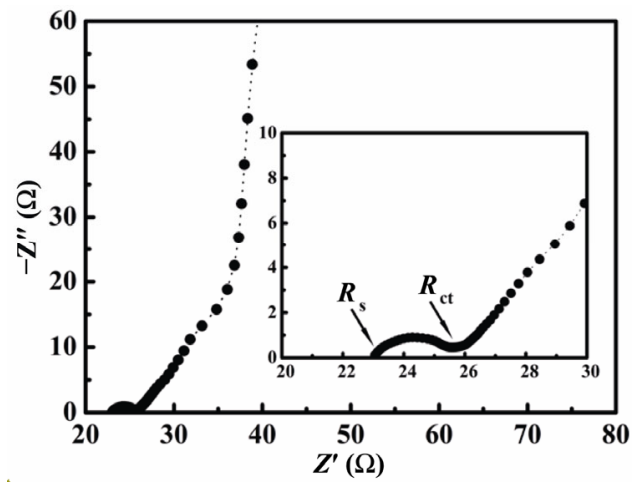

Fig. 7 EIS curves of VN nanofiber-based all-solid-state SCs nitrided at $550{ }^{\circ} \mathrm{C}$ with $\mathrm{LiCl} / \mathrm{PVA}$ electrolyte. Inset: EIS curves at high frequency.

all-solid-state SCs.

The electrochemical impedance spectroscopy (EIS) measurement was performed to study the electrochemical and ion transport behavior of the VN nanofiber-based all-solid-state SCs. As shown in Fig. 7 and Fig. S4 in the ESM, a nearly vertical line in the low-frequency region and a semicircle shape at the high-frequency range are observed, which is indicative of a relatively ideal double-layer capacitance property of the VN nanofibers. The first intersection with the $x$-axis at the highest frequency represents a combined electric resistance $\left(R_{\mathrm{s}}\right)$, consisting of the inherent and ionic resistance of the electrode materials and the electric resistance of the connection between the current collector and the electrolyte [50]. $R_{\mathrm{s}}$ for the VN nanofiber-based all-solid-state SCs nitrided at $550{ }^{\circ} \mathrm{C}$ is $23.05 \Omega$, indicating lower equivalent series resistance (ESR) compared with the ones nitrided at 600 and $650{ }^{\circ} \mathrm{C}$ with 33.1 and $35.4 \Omega$ respectively. The lower ESR makes electric ion easily go through the interface between the electrode and electrolyte [51,52]. Besides, the semicircle shape appearing at the high frequency range indicates the interfacial charge-transfer resistance $\left(R_{\mathrm{ct}}\right)$ ascribed to the double-layer mechanism. The $R_{\mathrm{ct}}$ of $4.24 \Omega$ reveals the good ion transport diffusion of the VN nanofibers nitrided at $550{ }^{\circ} \mathrm{C}$. Both the low $R_{\mathrm{s}}$ and $R_{\mathrm{ct}}$ add to the virtues of $\mathrm{VN}$ nanofiber-based allsolid-state SCs.

To gain a further insight into the potential of $\mathrm{VN}$ nanofibers as electrode for all-solid-state SCs, the cycle performance for $\mathrm{VN}$ nanofiber-based all-solidstate SCs is of vital importance. Similar to battery, the long-term cycle stability is crucial for practical applications of SCs. The cycle life test was conducted through repeating GDC measurements of the VN nanofiber-based SCs between 0 and $1.0 \mathrm{~V}$ at a current density of $1 \mathrm{~A} / \mathrm{g}$ for 2000 cycles. As depicted in Fig. 8(a), the VN nanofiber-based all-solid-state SCs exhibit an excellent cycling stability, with $24.9 \%$ loss of capacitance after 2000 cycles. This good cycle performance can be contributed to the chemically stable VN nanofibers. Meanwhile, the energy and power density are another two important parameters for assessing the electrochemical performance of assembled all-solid-state SCs. The energy density and power density of the VN nanofiber-based all-solid-state SCs could be calculated from their GDC curves according to the following equations:

$$
\begin{gathered}
E=\frac{I \times \Delta V \times \Delta t}{2 A d} \\
P=E / \Delta t
\end{gathered}
$$

where $E$ is the energy density $\left(\mathrm{W} \cdot \mathrm{h} / \mathrm{cm}^{3}\right), P$ is the power density $\left(\mathrm{W} / \mathrm{cm}^{3}\right), I$ is the constant current (A), $\Delta V$ is the potential window after "IR drop" $(\mathrm{V}), \Delta t$ is the discharging time (h), $A$ is the coating area $\left(\mathrm{cm}^{2}\right)$ of VN nanofibers on ITO glass equivalent to $1 \mathrm{~cm} \times 1 \mathrm{~cm}$, and $d$ is the average thickness of electrode materials
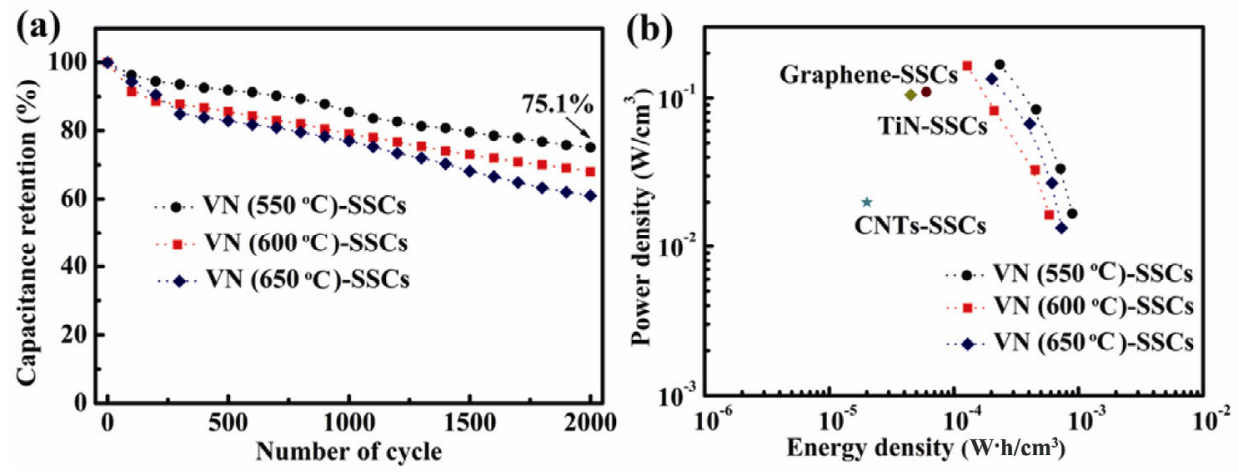

Fig. 8 (a) Cycle performance and (b) Ragone plot of VN nanofiber-based all-solid-state SCs. Energy and power densities of recently reported symmetric all-solid-state SCs are provided for comparison. 
(cm). The results are plotted in Fig. 8(b). Notably, the maximum energy density of $0.89 \mathrm{~mW} \cdot \mathrm{h} / \mathrm{cm}^{3}$ and the power density of $0.016 \mathrm{~W} / \mathrm{cm}^{3}$ are achieved at an operating potential within $1.0 \mathrm{~V}$, which exceeds the volumetric energy densities for the reported symmetric all-solid-state SCs, such as TiN nanowire-based symmetric SCs $\left(c a .0 .045 \mathrm{~mW} \cdot \mathrm{h} / \mathrm{cm}^{3}\right)$ [53], graphene symmetric SCs $\left(c a .0 .06 \mathrm{~mW} \cdot \mathrm{h} / \mathrm{cm}^{3}\right)$ [54], and CNTs symmetric SCs $\left(c a .0 .02 \mathrm{~mW} \cdot \mathrm{h} / \mathrm{cm}^{3}\right)$ [55]. Considering their long-term cycle life together with high energy and power density, $\mathrm{VN}$ nanofibers are anticipated to serve as an alternative high performance electrode for the SCs.

\section{Conclusions}

In summary, polyporous VN nanofibers have been successfully synthesized by a versatile electrospinning method followed by nitridation in ammonia atmosphere. The obtained VN nanofibers were further assembled into all-solid-state SCs and achieved a high capacitance value of $110.8 \mathrm{~F} / \mathrm{g}$. Additionally, the assembled VN nanofiber-based symmetric all-solid-state SCs reached a considerable volume energy of $0.89 \mathrm{~mW} \cdot \mathrm{h} / \mathrm{cm}^{3}$ and a power density of $0.016 \mathrm{~W} / \mathrm{cm}^{3}$. More importantly, the assembled all-solid-state SCs also exhibited an excellent cycling stability, with $24.9 \%$ loss of capacitance after 2000 cycles. These results demonstrate that the electrospun VN nanofibers could be potentially used for energy storage devices.

\section{Acknowledgements}

This study was supported by the Young Elite Scientists Sponsorship Program by CAST (Grant No. 2017QNRC001) and the National Natural Science Foundation of China (Grant No. 51402116). The authors thank the Analytical and Testing Center of Huazhong University of Science and Technology for support, specially appreciating Mr. Zhao for the help of TEM analysis.

\section{Electronic Supplementary Material}

Supplementary material is available in the online version of this article at https://doi.org/10.1007/s40145-018-0276 -2 .

\section{References}

[1] Xiao X, Li T, Yang P, et al. Fiber-based all-solid-state flexible supercapacitors for self-powered systems. ACS Nano 2012, 6: 9200-9206.

[2] $\mathrm{Hu} \mathrm{S}, \mathrm{Li} \mathrm{H}, \mathrm{Su} \mathrm{Z}$, et al. Facile synthesis of highly conductive $\mathrm{Ag} / \mathrm{TiN}$ nanofibers for cost-saving transparent electrodes. RSC Adv 2016, 6: 85041-85045.

[3] Li H, Sun Y, Zhang W, et al. Preparation of heterostructured $\mathrm{Ag} / \mathrm{BaTiO}_{3}$ nanofibers via electrospinning. J Alloys Compd 2010, 508: 536-539.

[4] Xie Y, Tian F. Capacitive performance of molybdenum nitride/titanium nitride nanotube array for supercapacitor. Mat Sci Eng B 2017, 215: 64-70.

[5] Gao Y, Wang L, Li Z, et al. Electrochemical performance of $\mathrm{Ti}_{3} \mathrm{C}_{2}$ supercapacitors in $\mathrm{KOH}$ electrolyte. $J$ Adv Ceram 2015, 4: 130-134.

[6] Kim JH, Yoon JR. Preparation and characterization of $\mathrm{Li}_{4} \mathrm{Ti}_{5} \mathrm{O}_{12}$ synthesized using hydrogen titanate nanowire for hybrid super capacitor. J Adv Ceram 2013, 2: 285-290.

[7] Shah SIU, Hector AL, Owen JR. Redox supercapacitor performance of nanocrystalline molybdenum nitrides obtained by ammonolysis of chloride- and amide-derived precursors. J Power Sources 2014, 266: 456-463.

[8] Ruan D, Lin R, Jiang K, et al. High-performance porous molybdenum oxynitride based fiber supercapacitors. ACS Appl Mater Interfaces 2017, 9: 29699-29706.

[9] Zheng Z, Retana M, Hu X, et al. Three-dimensional cobalt phosphide nanowire arrays as negative electrode material for flexible solid-state asymmetric supercapacitors. ACS Appl Mater Interfaces 2017, 9: 16986-16994.

[10] Vijayan S, Kirubasankar B, Pazhamalai P, et al. Electrospun $\mathrm{Nd}^{3+}$-doped $\mathrm{LiMn}_{2} \mathrm{O}_{4}$ nanofibers as highperformance cathode material for Li-ion capacitors. Chemelectrochem 2017, 4: 2059-2067.

[11] Chen L, Liu C, Zhang Z. Novel [111] oriented $\gamma-\mathrm{Mo}_{2} \mathrm{~N}$ thin films deposited by magnetron sputtering as an anode for aqueous micro-supercapacitors. Electrochim Acta 2017, 245: 237-248.

[12] Wang L, Feng X, Ren L, et al. Flexible solid-state supercapacitor based on a metal-organic framework interwoven by electrochemically-deposited PANI. $\mathrm{J} \mathrm{Am}$ Chem Soc 2015, 137: 4920-4923.

[13] Gogotsi Y. Energy storage wrapped up. Nature 2014, 509: 568-570.

[14] Yu G, Hu L, Liu N, et al. Enhancing the supercapacitor performance of graphene $/ \mathrm{MnO}_{2}$ nanostructured electrodes by conductive wrapping. Nano Lett 2011, 11: 4438-4442.

[15] Wang G, Zhang L, Zhang J. A review of electrode materials for electrochemical supercapacitors. Chem Soc Rev 2012, 41: 797-828.

[16] Wang H, Zhi L, Liu K, et al. Carbon nanomeshes: Thinsheet carbon nanomesh with an excellent electrocapacitive performance. Adv Funct Mater 2015, 25: 5406-5406.

[17] Wei F, Cui X, Chen W, et al. Manganese oxide-based 
materials as electrochemical supercapacitor electrodes. Chem Soc Rev 2011, 40: 1697-1721.

[18] Wei T-Y, Chen C-H, Chien H-C, et al. A cost-effective supercapacitor material of ultrahigh specific capacitances: Spinel nickel cobaltite aerogels from an epoxide-driven sol-gel process. Adv Mater 2010, 22: 347-351.

[19] Kirubasankar B, Murugadoss V, Angaiah S. Hydrothermal assisted in situ growth of CoSe onto graphene nanosheets as a nanohybrid positive electrode for asymmetric supercapacitors. RSC Adv 2017, 7: 5853-5862.

[20] Zhang LL, Zhao XS. Carbon-based materials as supercapacitor electrodes. Chem Soc Rev 2009, 38: 25202531.

[21] Zhou X, Shang C, Gu L, et al. Mesoporous coaxial titanium nitride-vanadium nitride fibers of core-shell structures for high-performance supercapacitors. ACS Appl Mater Interfaces 2011, 3: 3058-3063.

[22] Chen P, Li H, Hu S, et al. Copper-coated TiN nanofibers with high electrical conductivity: A new advance in conductive one-dimensional nanostructures. J Mater Chem C 2015, 3: 7272-7276.

[23] Kumar M, Subramania A, Balakrishnan K. Preparation of electrospun $\mathrm{Co}_{3} \mathrm{O}_{4}$, nanofibers as electrode material for high performance asymmetric supercapacitors. Electrochim Acta 2014, 149: 152-158.

[24] Devadas A, Baranton S, Napporn TW, et al. Tailoring of $\mathrm{RuO}_{2}$ nanoparticles by microwave assisted "Instant method" for energy storage applications. J Power Sources 2011, 196: 4044-4053.

[25] Hanumantha PJ, Datta MK, Kadakia K, et al. Vanadium nitride supercapacitors: Effect of processing parameters on electrochemical charge storage behavior. Electrochim Acta 2016, 207: 37-47.

[26] Xia C, Xie Y, Du H, et al. Ternary nanocomposite of polyaniline/manganese dioxide/titanium nitride nanowire array for supercapacitor electrode. J Nanopart Res 2015, 17: 30 .

[27] Liu J, Huang K, Tang HL, et al. Porous and singlecrystalline-like molybdenum nitride nanobelts as a non-noble electrocatalyst for alkaline fuel cells and electrode materials for supercapacitors. Int $J$ Hydrogen Energ 2016, 41: 996-1001.

[28] Nandi DK, Sen UK, Sinha S, et al. Atomic layer deposited tungsten nitride thin films as a new lithium-ion battery anode. Phys Chem Chem Phys 2015, 17: 17445-17453.

[29] Bouhtiyya S, Porto RL, Laïk B, et al. Application of sputtered ruthenium nitride thin films as electrode material for energy-storage devices. Scripta Mater 2013, 68: 659662.

[30] Sun Z, Zhang J, Yin L, et al. Conductive porous vanadium nitride/graphene composite as chemical anchor of polysulfides for lithium-sulfur batteries. Nat Commun 2017, 8: 14627.

[31] Choi D, Blomgren GE, Kumta PN. Fast and reversible surface redox reaction in nanocrystalline vanadium nitride supercapacitors. Adv Mater 2006, 18: 1178-1182.

[32] Zhou X, Chen H, Shu D, et al. Study on the electrochemical behavior of vanadium nitride as a promising supercapacitor material. J Phys Chem Solids 2009, 70: 495-500.

[33] Lu X, Yu M, Zhai T, et al. High energy density asymmetric quasi-solid-state supercapacitor based on porous vanadium nitride nanowire anode. Nano Lett 2013, 13: 2628-2633.

[34] Xiao X, Peng X, Jin H, et al. Freestanding mesoporous VN/CNT hybrid electrodes for flexible all-solid-state supercapacitors. Adv Mater 2013, 25: 5091-5097.

[35] $\mathrm{Li} \mathrm{H}, \mathrm{Wu} \mathrm{H}$, Lin $\mathrm{D}$, et al. High $T_{\mathrm{c}}$ in electrospun $\mathrm{BaTiO}_{3}$ nanofibers. J Am Ceram Soc 2009, 92: 2162-2164.

[36] Chen $\mathrm{P}, \mathrm{Hu} \mathrm{S}$, Zhou T, et al. $\mathrm{Cu} / \mathrm{TiN}$ nanofiber with tunable electrical conductivity for cost-efficient transparent electrode. Chem Eng J 2016, 306: 139-145.

[37] Li H, Zhang W, Li B, et al. Diameter-dependent photocatalytic activity of electrospun $\mathrm{TiO}_{2}$ nanofiber. $\mathrm{J} \mathrm{Am}$ Ceram Soc 2010, 93: 2503-2506.

[38] Solarajan AK, Murugadoss V, Angaiah S. Dimensional stability and electrochemical behaviour of $\mathrm{ZrO}_{2}$ incorporated electrospun PVdF-HFP based nanocomposite polymer membrane electrolyte for Li-ion capacitors. $\mathrm{Sci}$ Rep 2017, 7: 45390.

[39] Reneker DH, Chun I. Nanometre diameter fibres of polymer, produced by electrospinning. Nanotechnology 1996, 7: 216-223.

[40] Li H, Zhang W, Huang S, et al. Enhanced visible- lightdriven photocatalysis of surface nitrided electrospun $\mathrm{TiO}_{2}$ nanofibers. Nanoscale 2012, 4: 801-806.

[41] Blackburn BJ, Crane JH, Knapp CE, et al. Reactivity of vanadium oxytrichloride with $\beta$-diketones and diesters as precursors for vanadium nitride and carbide. Mater Design 2016, 108: 780-790.

[42] Fu H, Yang X, An X, et al. Experimental and theoretical studies of $\mathrm{V}_{2} \mathrm{O}_{5} @ \mathrm{TiO}_{2}$, core-shell hybrid composites with high gas sensing performance towards ammonia. Sensor Actuat B-Chem 2017, 252: 103-115.

[43] Yan X, Xue C, Yang B, et al. Novel three-dimensionally ordered macroporous $\mathrm{Fe}^{3+}$-doped $\mathrm{TiO}_{2}$ photocatalysts for $\mathrm{H}_{2}$ production and degradation applications. Appl Surf Sci 2017, 394: 248-257.

[44] Lin B, An H, Yan X, et al. Fish-scale structured $\mathrm{g}-\mathrm{C}_{3} \mathrm{~N}_{4}$ nanosheet with unusual spatial electron transfer property for high-efficiency photocatalytic hydrogen evolution. Appl Catal B-Environ 2017, 210: 173-183.

[45] Koh K, Wong-Foy AG, Matzger AJ. A porous coordination copolymer with over $5000 \mathrm{~m}^{2} / \mathrm{g}$ BET surface area. $\mathrm{J} \mathrm{Am}$ Chem Soc 2009, 131: 4184-4185.

[46] Chen Q, Liu Q, Chu X, et al. Ultrasonic-assisted solution combustion synthesis of porous $\mathrm{Na}_{3} \mathrm{~V}_{2}\left(\mathrm{PO}_{4}\right)_{3} / \mathrm{C}$ : Formation mechanism and sodium storage performance. $J$ Nanopart Res 2017, 19: 146.

[47] Chea JS, Kwon H-N, Yoon W-S, et al. Non-aqueous quasi-solid electrolyte for use in supercapacitors. $J$ Ind Eng Chem 2018, 59: 192-195. 
[48] Wu Q, Xu Y, Yao Z, et al. Supercapacitors based on flexible graphene/polyaniline nanofiber composite films. ACS Nano 2010, 4: 1963-1970.

[49] Han Y, Ge Y, Chao Y, et al. Recent progress in 2D materials for flexible supercapacitors. J Energy Chem 2018, 27: 57-72.

[50] Tseng L-H, Hsiao C-H, Nguyen DD, et al. Activated carbon sandwiched manganese dioxide/graphene ternary composites for supercapacitor electrodes. Electrochim Acta 2018, 266: 284-292.

[51] Li X, Wang Z, Guo L, et al. Manganese oxide/hierarchical porous carbon nanocomposite from oily sludge for high-performance asymmetric supercapacitors. Electrochim Acta 2018, 265: 71-77.

[52] Navalpotro P, Anderson M, Marcilla R, et al. Insights into the energy storage mechanism of hybrid supercapacitors with redox electrolytes by electrochemical impedance spectroscopy. Electrochim Acta 2018, 263: 110-117.
[53] Lu X, Wang G, Zhai T, et al. Stabilized TiN nanowire arrays for high-performance and flexible supercapacitors. Nano Lett 2012, 12: 5376-5381.

[54] El-Kady MF, Veronica S, Sergey D, et al. Laser scribing of high-performance and flexible graphene-based electrochemical capacitors. Science 2012, 335: 1326-1330.

[55] Kaempgen M, Chan CK, Ma J, et al. Printable thin film supercapacitors using single-walled carbon nanotubes. Nano Lett 2009, 9: 1872-1876.

Open Access The articles published in this journal are distributed under the terms of the Creative Commons Attribution 4.0 International License (http://creativecommons.org/licenses/by/4.0/), which permits unrestricted use, distribution, and reproduction in any medium, provided you give appropriate credit to the original author(s) and the source, provide a link to the Creative Commons license, and indicate if changes were made. 